\title{
Study on S-4-methylbenzyl-O,O'-dithiophosphates as Corrosion Inhibitors for Q235 steel in HCl Solution
}

\author{
Chuan Lai ${ }^{1,3}$, Jian Wei $i^{3}$, Xiaogang Guo ${ }^{2}$, Bin Xie ${ }^{3, *}$, Like Zou ${ }^{3}$, Xiao Ma ${ }^{3}$, Shasha Zhu ${ }^{3}$, \\ Luo Chen ${ }^{1}$, Guangbing Luo ${ }^{1}$ \\ ${ }^{1}$ School of Chemistry and Chemical Engineering, Eastern Sichuan Sub-center of National Engineering \\ Research Center for Municipal Wastewater Treatment and Reuse, Sichuan University of Arts and \\ Science, Dazhou 635000, PR China \\ ${ }^{2}$ College of Chemistry and Chemical Engineering, Yangtze Normal University, Fuling, 408003, PR \\ China \\ ${ }^{3}$ Institute of Functional Materials, Material Corrosion and Protection Key Laboratory of Sichuan \\ Province, Sichuan University of Science and Engineering, Zigong 643000, PR China \\ *E-mail: xiebinsuse@163.com
}

doi: $10.20964 / 2017.11 .16$

Received: 21 July 2017 / Accepted: 29 August 2017 / Published: 12 October 2017

Herein, S-4-methylbenzyl-O,O'-bis(4-nitrophenyl)dithiophosphate (SBOP-I) and S-4-methylbenzylO,O'-bis(4-t-butylphenyl)dithiophosphate (SBOP-II) were synthesized and characterized. Meanwhile, the new corrosion inhibitors for Q235 steel in $\mathrm{HCl}$ solution were evaluated by weight loss method and electrochemical measurements. Electrochemical measurements indicate that the inhibitors are mixedtype inhibitor, the inhibition efficiency increase with the concentration of inhibitor increase, decrease with the $\mathrm{HCl}$ concentration and temperature increasing. Weight loss measurement results show that the adsorption of SBOP-I and SBOP-II on Q235 steel surface obeys Langmuir isotherm, which belongs to chemical adsorption.

Keywords: Corrosion inhibitor; Electrochemical; Weight loss; Q235 steel; Langmuir.

\section{$\underline{\text { FULL TEXT }}$}

(C) 2017 The Authors. Published by ESG (www.electrochemsci.org). This article is an open access article distributed under the terms and conditions of the Creative Commons Attribution license (http://creativecommons.org/licenses/by/4.0/). 